\title{
Blastomycosis of the colon resembling clinically ulcerative colitis
}

\author{
F. J. PENNA ${ }^{1}$ \\ From Departamento de Pediatria, Faculdade de Medicina, \\ Universidade Federal de Minas Gerais, Brazil
}

SUMMARY An 8 year old Brazilian girl had an infection, apparently confined to the large intestine, with Paracoccidioides brasiliensis. The symptons were diarrhoea with fresh blood and mucus, severe malnutrition, and a spastic and ulcerated colon. She is making good progress on co-trimoxazole.

South American blastomycosis is a systemic mycosis caused by infection with Paracoccidioides brasiliensis and is endemic in humid tropical and subtropical zones of continental Latin America, particularly in Brazil (Mackinnon, 1972). Many aspects of this disease are discussed in two symposia (Proceedings of the International Symposium on Mycoses, 1970; Proceedings of the First Pan American Symposium, 1972). There is an extensive bibliography (Al-Doory and Pairon, 1975). It occurs predominantly among rural agricultural workers. However, the organism has been isolated only with some difficulty from the soil in endemic areas (Albornoz, 1972). In the classical form of the disease the suppurative granulomatous lesions are found in the mucous membranes of the oropharynx, the skin especially around the lips and nose, lymph glands, lungs, adrenals, intestine, pancreas, spleen, and liver. Other organs such as the testes, brain, cerebellum, meninges, bones, heart, and large arteries are seldom involved. The disease is most commonly recognised from the mucous lesions in the oropharynx, cervical adenitis, and respiratory symptoms, but it may present in various guises (Restrepo et al., 1976). In adults men are attacked at least 10 times as frequently as women. The disease is rare in children (say $5 \%$ of patients), occurs equally often in girls and boys, and typically involves the lymph nodes: mucous membranes and lung are rarely affected (Castro and Del Negro, 1976). Peña (1967) among 72 cases had only one female patient and none under the age of 17 years. General symptoms include fever,

${ }^{1}$ Present address: Gastrointestinal Unit, Division of Clinical Sciences, Clinical Research Centre, Harrow, Middlesex HA1 3UJ.

Address for reprint requests: Dr. F. J. Penna, Rua dos Otoni 818, Belo Horizonte-CEP 30.000, Minas Gerais, Brazil. Received for publication 28 February 1979. weight loss, weakness, and prostration. The disease must be differentiated from tuberculosis and malignant disease.

We here report a case of South American blastomycosis in an 8 year old girl which gave a clinical picture resembling ulcerative colitis. Gut involvement is rare, especially in children, and is almost always associated with lesions elsewhere.

\section{Case report}

The patient was referred to our clinic with diarrhoea, failure to thrive, and anorexia. She had the appearance of severe malnutrition (Fig. 1), and her height $(110 \mathrm{~cm})$ and weight $(14.8 \mathrm{~kg})$ were below the third percentile for her age ( 8 years). She was the youngest of five children of middle class parents living in a small town in the north of the state of Minas Gerais, Brazil. The parents and other children were healthy. Her development had been normal until she was 4 years old when, after an attack of measles, she developed diarrhoea. At first the number of motions passed was not very large, but undigested food particles were present. The frequency had increased and at the time of examination she was passing about 10 small motions during the day and three to four during the night. The stools were semi-liquid and contained mucus, blood and occasionally pus. Blood was sometimes passed on its own. There was persistent abdominal pain, and colic when passing motions. Periodically the symptoms intensified and she had increased abdominal distension and fever. She had been given three blood transfusions and had twice been admitted to hospital. Clinical examination showed severe wasting with a distended abdomen, prostration, walking only with difficulty and pallid skin and mucosa.

Serum protein determinations gave the following 


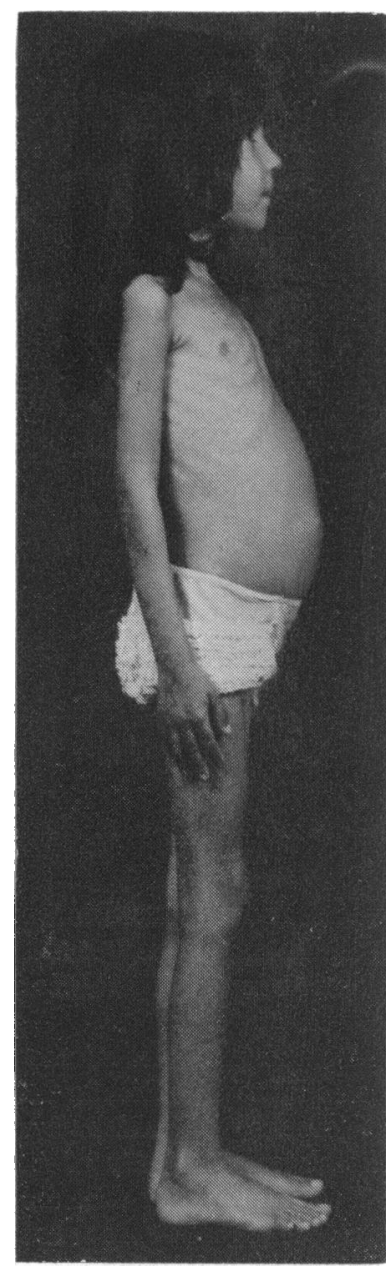

Fig. 1 Patient showing severe secondary malnutrition (height $110 \mathrm{~cm}$, weight $14.8 \mathrm{~kg}$, age 8 years).

results (in g/l): total proteins, 72 ; albumin, $24 \cdot 8 ; \alpha_{1}$ globulin, $2 \cdot 7 ; \alpha_{2}$-globulin, $7 \cdot 1 ; \beta$-globulin, 7.4; $\gamma$-globulin, $30 \cdot 0$. Thus there was a greatly raised level of $\gamma$-globulin and a reduction in albumin. Haematological investigations gave: $\mathrm{Hb}, 107 \mathrm{~g} / \mathrm{l}$; PCV, 34\%; ESR, $101 \mathrm{~mm} / \mathrm{h}$; leucocyte counts normal. Faecal fat was normal. Barium enema showed superficial and deep ulcerations (Fig. 2) involving the entire colon and caecum. The terminal ileum, caecum and the ascending colon were irritable and spastic. The radiograph of the chest was normal. The suggested differential diagnosis on radiography was: ulcerative colitis, Crohn's disease, amoebiasis, blastomycosis, and trichiuriasis. Colonoscopy showed rectal narrowing for $6 \mathrm{~cm}$ from the anus; the colonoscope could be passed only with difficulty and was passed only as far as the splenic flexure. Superficial and deep ulcerations were seen, together with some normal areas. Biopsies were taken from the edges of the ulcerations.

Histological examination of the biopsies showed blastomycosis with the presence of large numbers of Paracoccidioides brasiliensis (Fig. 3). The diagnosis was supported by complement fixation which was positive at a dilution of $1 / 8$. A negative test would have made the diagnosis improbable, but infection with other cross-reacting fungi can also give positive tests (see Kaufman, 1972; Fava Netto, 1976).

\section{TREATMENT}

Sulphamethoxazole $(400 \mathrm{mg}$ ) and trimethoprim $(80 \mathrm{mg})$ was given as Bactrim (Roche), twice daily continuously for two years, with haematological checks monthly.

\section{PROGRESS}

There was immediate improvement of intestinal function, with normal stools being passed within a few days. After 10 weeks she was free of clinical manifestations and weighed $17 \mathrm{~kg}$ (a gain of $2 \cdot 2 \mathrm{~kg}$ ).

\section{Discussion}

In this patient blastomycosis affecting only the colon gave a clinical picture resembling ulcerative colitis.

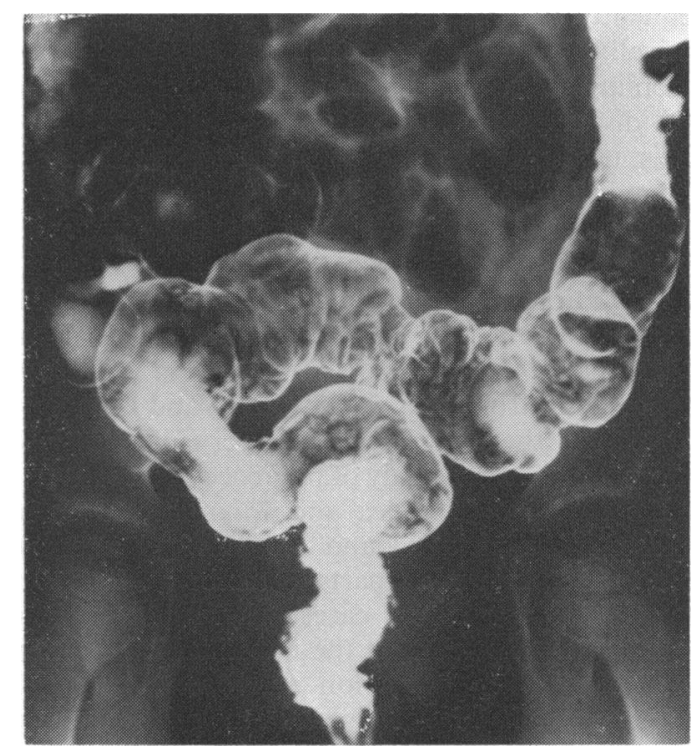

Fig. 2 Radiograph showing irregular ulcerated contour of the rectum associated with narrowing. 


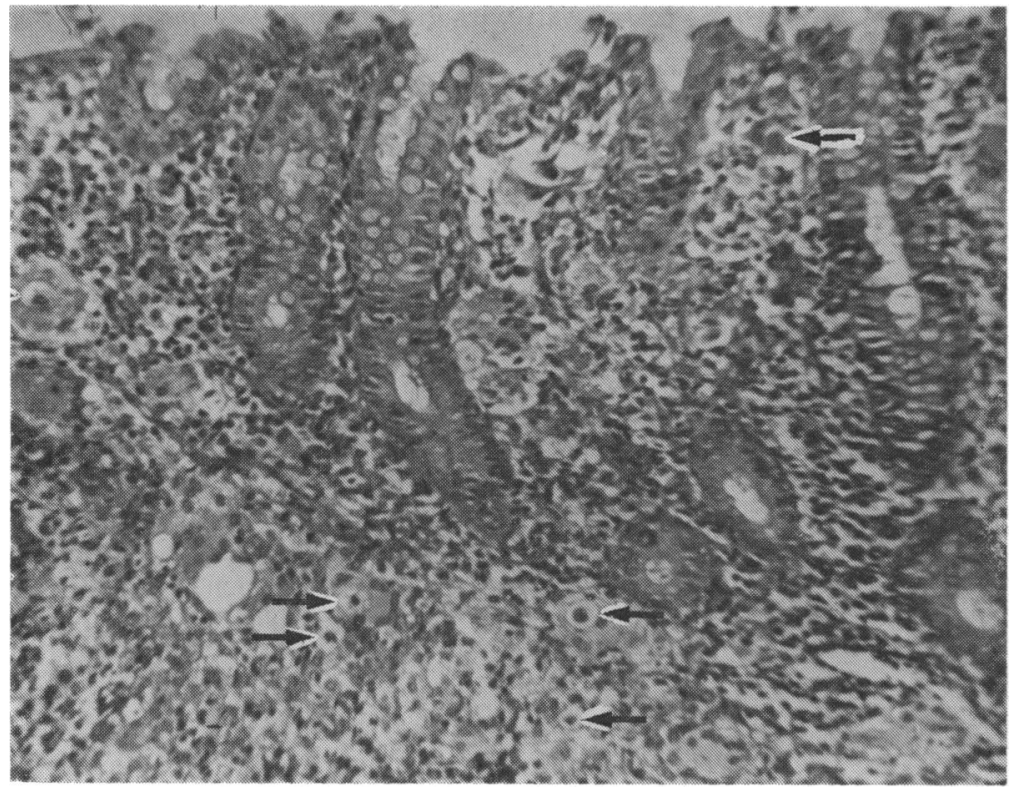

Fig. 3 Biopsy from colon, stained with $H$ and $E$, showing ulceration and presence of many fungal cells (some marked with arrows).
It must therefore be considered in differential diagnosis. Although blastomycosis is common only in South and Central America, it is occasionally reported in the United States (for example, Hughes et al., 1969; Kroll and Walzer, 1972; Murray et al., 1974), and in Europe (see Mackinnon, 1972). With increased travel the disease is likely to be found more frequently in other countries, and it may persist in a clinically inapparent form for several decades before becoming overt (Mackinnon, 1970). Tropical parasitic disease (schistosomiasis, amoebiasis, balantidiasis, trichiurasis) would also need to be considered in the differential diagnosis.

The manifestation of infection with Paracoccidioides brasiliensis was highly unusual in this patient. The traditional picture was derived from the study of adult patients (see, for example, Machado Filho and Lisbôa Miranda, 1960; Restrepo et al., 1970), and it is clear from the work of Castro and Del Negro (1976) that the disease presents very differently in children. In a recent study of paracoccidioidomycosis of the intestine (Fonseca and Mignone, 1976) no children were included and only limited attention paid to lesions in other parts of the body. However, they do report seven cases where post-mortem examination showed that the intestinal involvement was confined to the colon and one 16 year old labourer who had involvement of the small and large intestine. In the series of 52 children (aged 14 years and under) studied by Castro and Del Negro the organs most involved were the lymph nodes; in only one of them was abdominal involvement the presenting symptom. In the patient reported here thorough clinical examination revealed no lesions other than in the large bowel.

There remains the problem of the route of infection. Machado Filho and Lisbôa Miranda (1960) recorded the organs in which symptoms first developed. These were (in order of frequency) oral cavity, lung, larynx, lymph node, skin, nose, and intestine. They concluded that chewing infected grasses, inhalation, or contamination of skin lesions were the probable routes of infection. Mackinnon (1959), using very large inocula in mice, concluded that the lung was the only probable portal of entry, and Giraldo et al. (1976) emphasised the role of the lung in their patients (for a general discussion see Furtado, 1975). However, as the pattern of disease is different in children, it seems possible that there are two main routes of infection, as with Mycobacterium tuberculosis. The adult pattern might correspond with pulmonary tuberculosis and the child pattern to mediastinal and other lymph node involvement after ingestion. It is possible that our patient had been infected by swallowing the fungus, and if the intestinal lesion was primary no apparent spread was noted. There were no lung symptoms and no lung lesions detectable on radiography. She lived in a hygienic environment and had no known contact with recognised sources of infection.

I am grateful to Mr. D. Kingston and Dr. M. Shiner 
for help in writing this paper. I acknowledge with gratitude the receipt of a scholarship from the Conselho Nacional de Desenvolvimento Cientifico e Tecnológico (of Brazil) which enabled me to spend a year at the Clinical Research Centre, Harrow.

\section{References}

Al-Doory, Y., and Pairon, R. (1975). A bibliography of blastomycosis and paracoccidioidomycosis. Mycopathologia, 56, 159-206.

Albornoz, M. B. de (1972). Isolation of Paracoccidioides brasiliensis from rural soil in Venezuela. In Paracoccidiodomycosis: Proceedings of the First Pan American Symposium. (Pan American Sanitary Bureau, Scientific Publication No. 254), pp. 71-75. Pan American Health Organisation: Washington D. C.

Castro, R. M., and Del Negro, G. (1976). Particularidades Clínicas da Paracoccidioidomicose na Criança. Revista do Hospital das Clinicas da Faculdade de Medicina de Sao Paulo, 31, 194-198.

Fava Netto, C. (1976). Immunologia da paracoccidioidomicose. Revista do Instituto de Medicina Tropical de Sao Paulo, 18, 42-53.

Fonseca, L. C., and Mignone, C. (1976). Paracoccidioidomicose do intestino delgado. Revista do Hospital das Clinicas da Faculdade de Medicina de Sao Paulo, 31, 199207.

Furtado, T. (1975). Infection versus disease in South American blastomycosis. International Journal of Dermatology, 14, 117-125.

Giraldo, R., Restrepo, A., Gutiérrez, F., Robledo, M., Londoño, F., Hernández, H., Sierra, F., and Calle, G. (1976). Pathogenesis of paracoccidioidomycosis: a model based on the study of 46 patients. Mycopathologia, 58, 63-70.

Hughes, W. T., Franco, S., and Oh, M. H. K. (1969). Systematic blastomycosis in childhood. Case report and review. Clinical Pediatrics, 8, 597-601.

Kaufman, L. (1972). Evaluation of serological tests for paracoccidioidomycosis: preliminary report. In Paracoccidioidomycosis: Proceedings of the First Pan American Symposium. (Pan American Sanitary Bureau, Scientific
Publication No. 254), pp. 221-226. Pan American Health Organisation: Washington D.C.

Kroll, J. J., and Walzer, R. A. (1972). Paracoccidioidomycosis in the United States. Archives of Dermatology, 106, 543-546.

Machado Filho, J., and Lisbôa Miranda, J. (1960). Consideraçoes relativas à blastomicose Sul-Americana. Localizaçoes, sintomas iniciais, vias de penetração e disseminação em 313 casos consecutivos. O Hospital, 58, 99-137.

Mackinnon, J. E. (1959). Pathogenesis of South American blastomycosis. Transactions of the Royal Society of Tropical Medicine and Hygiene, 53, 487-494.

Mackinnon, J. E. (1970). On the importance of South American blastomycosis. Mycopathologia et Mycologia Applicata, 41, 187-193.

Mackinnon, J. E. (1972). Geographical distribution and prevalence of paracoccidioidomycosis. In Paracoccidioidomycosis: Proceedings of the First Pan American Symposium. (Pan American Sanitary Bureau, Scientific Publication No. 254), pp. 45-52. Pan American Health Organisation: Washington D.C.

Murray, H. W., Littman, M. L., and Roberts, R. B. (1974). Disseminated paracoccidioidomycosis (South American blastomycosis) in the United States. American Journal of Medicine, 56, 209-220.

Pan American Sanitary Bureau, Paracoccidioidomycosis: Proceedings of the First Pan American Symposium. (Scientific Publication No. 254), Pan American Health Organisation: Washington D.C., 1972.

Peña, C. E. (1967). Deep myotic infections in Colombia. A clinicopathologic study of 162 cases. American Journal of Clinical Pathology, 47, 505-520.

Proceedings of the International Symposium on Mycoses. (Pan American Sanitary Bureau, Scientific Publication No. 205), Pan American Health Organisation: Washington D.C., 1970.

Restrepo, A., Robledo, M., Giraldo, R., Hernández, H., Sierra, F., Gutiérrez, F., Londoño, F., López, R., and Calle, G. (1976). The gamut of paracoccidioidomycosis. American Journal of Medicine, 61, 33-42.

Restrepo, A., Robledo, M., Gutiérrez, F., Sanclemente, M., Castañeda, E., and Calle, G. (1970). Paracoccidioidomycosis (South American blastomycosis). A study of 39 cases observed in Medellín, Colombia. American Journal of Tropical Medicine and Hygiene, 19, 68-76. 